\title{
Determination of Spectral Markers of Cytotoxicity and Genotoxicity Using in vitro Raman Microspectroscopy: Cellular Responses to Polyamidoamine Dendrimer Exposure
}

\author{
Esen Efeoglu \\ Technological University Dublin, esen.efeoglu@tudublin.ie \\ Alan Casey \\ Technological University Dublin, alan.casey@tudublin.ie \\ Hugh J. Byrne \\ Technological University Dublin, hugh.byrne@tudublin.ie
}

Follow this and additional works at: https://arrow.tudublin.ie/biophonart

Part of the Medicine and Health Sciences Commons, and the Physics Commons

\section{Recommended Citation \\ Efeoglu, E., Casey, A. \& Byrne, H.J. (2017). Determination of spectral markers of cytotoxicity and genotoxicity using in vitro raman microspectroscopy: cellular responses to polyamidoamine dendrimer exposure, The AnalystAugust, 2017. doi:10.1039/C7AN00969K}

This Article is brought to you for free and open access by the DIT Biophotonics and Imaging at ARROW@TU Dublin. It has been accepted for inclusion in Articles by an authorized administrator of ARROW@TU Dublin. For more information, please contact arrow.admin@tudublin.ie, aisling.coyne@tudublin.ie,gerard.connolly@tudublin.ie.

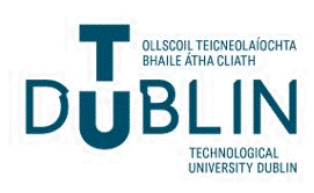




\title{
Determination of Spectral Markers of Cytotoxicity and Genotoxicity Using
} in vitro Raman Microspectroscopy: Cellular Responses to Polyamidoamine

\section{Dendrimer Exposure}

\author{
Esen Efeoglu ${ }^{1,2, *}$, Alan Casey ${ }^{1,2}$, Hugh J. Byrne ${ }^{2}$ \\ ${ }^{1}$ School of Physics, Dublin Institute of Technology, Kevin Street, Dublin 8, Ireland \\ ${ }^{2}$ FOCAS Research Institute, Dublin Institute of Technology, Kevin Street, Dublin 8, Ireland \\ *Corresponding Author: esen.efeoglu@mydit.ie
}

\begin{abstract}
Although consumer exposure to nanomaterials is ever increasing, with potential increased applications in areas such as drug and/or gene delivery, contrast agents and diagnosis, determination of cyto- and geno- toxic effect of nanomaterials on human health and the environment still remains challenging. Although many techniques have been established and adapted to determine the cytotoxicity and genotoxicity of nano-sized materials, these techniques remain limited by the number of assays required, total cost, use of labels and they struggle to explain the underlying interaction mechanisms. In this study, Raman microspectroscopy is employed as an in vitro label free high content screening technique to observe toxicological changes within the cell in a multi-parametric fashion. The evolution of spectral markers as a function of time and applied dose has been used to elucidate the mechanism of action of polyamidoamine (PAMAM) dendrimers associated with cytotoxicity and their impact on nuclear biochemistry. PAMAM dendrimers are chosen as a model nanomaterial due to their widely studied cytotoxic and genotoxic properties and commercial availability. Point spectra were acquired from cytoplasm to monitor the cascade of toxic
\end{abstract}


events occurring in the cytoplasm upon nanoparticle exposure, whereas the spectra acquired from nucleus and nucleolus were used to explore PAMAM-nuclear material interaction as well as genotoxic responses.

Keywords: Nanotoxicology, Raman microspectroscopy, Label free imaging, in vitro high content analysis, polyamidoamine (PAMAM) dendrimers, cytotoxicity, genotoxicity 


\section{Introduction}

The rapid advances in nanotechnology and potential exploitation of naturally occurring and engineered nanomaterials in various fields, from nanomedicine to diagnostics, ${ }^{1-3}$ has brought huge interest to the identification of their interaction with living systems and the environment. Nanotoxicology has been developed to monitor the behaviours of these unique materials inside living systems and to determine their mechanism of action. ${ }^{4,5}$ Many techniques from cytotoxicity, biochemical assays to bio-imaging techniques have been developed or adapted to investigate nanomaterials. However, these techniques remain limited due to the use of multiple labels, the number of assays required and analysis time. Although the analysis time has been reduced by the adaptation of a high content screening techniques (HCA/HCS) to elucidate nanomaterial toxicity, this technique still requires the use of labels and more development in terms of standardisation, the use of application specific models and data management, is needed. ${ }^{6}$

The potential of Raman microspectroscopy for the analysis of biological samples has already been demonstrated, including analysis of bodily fluids and cytological samples as well as tissue sectioning. ${ }^{7-10}$ Moreover, Raman microspectroscopy has been used to localise nanoparticles in cellular compartments. ${ }^{11-13}$ The dose and time dependent effects of aminated polystyrene nanoparticles (PS-NH$)$ on different cell lines has been spectroscopically characterised $^{14}$ and the mechanisms leading to cell death have been differentiated between cancerous and non-cancerous cell lines with the aid of multivariate analysis techniques. ${ }^{15}$

In the current study, the applicability of Raman microspectroscopy as a label-free and in vitro high content screening technique to identify spectral markers of cytotoxicity and genotoxicity is demonstrated. The systematic evolution of these spectral markers as a function of time and applied dose is shown for polyamidoamine (PAMAM) dendrimers. PAMAM nanoparticles 
have attracted attention in nanotechnology and nanomedicine due to their unique and tuneable properties. The potential use of PAMAM dendrimers in gene and/or drug delivery, miRNA delivery and MRI contrast agents has already been explored. ${ }^{16-18}$ The toxic effects of the PAMAM dendrimers on different cell lines have also been widely studied using cytotoxicity assays such as Alamar Blue (AB), MTT, Neutral Red (NR) and Clonogenic assays. ${ }^{19-24}$ Cellular exposure to PAMAM dendrimers has been shown to result in oxidative stress, activation of inflammatory cascades. As a general mechanism, dendrimers are found to cause a generation dependent, systematic cytotoxicity, oxidative stress and genotoxicity due to the proton sponge effect in endosomes and/or lysosomes, which causes lysosomal rupture and mitochondrial accumulation, resulting in cell death. Notably, PAMAM dendrimers were identified among the list of priority nanomaterials for nanotoxicological assessment, drawn up by the Organisation for Economic Co-operation and Development (OECD). ${ }^{25}$ Therefore, PAMAM dendrimers are chosen as model nanoparticles due to their widely studied and welldefined toxic properties and commercial availability.

In this study, A549, adenocarcinomic human alveolar basal epithelial cells, were used as a model cell line as they mimic one of the primary routes of nanoparticle exposure, inhalation and also for consistency with previous studies. ${ }^{11-15}$ PAMAM dendrimers elicit a systematic increase in toxicity with increasing generation, ${ }^{20}$ and Generation 5 dendrimers were chosen as they provide a mid-range toxic response. The cells are exposed to various doses of generation 5 PAMAM dendrimers (PAMAM-G5), from sub-lethal to lethal, for $24 \mathrm{~h}$ to observe dose dependant changes in the cytoplasmic and nuclear regions. A sub-lethal dose of PAMAM-G5 is also used to elucidate evolving biomolecular changes in the nucleus, nucleolus and cytoplasm, from 4 to 72 h. 20 point spectra were acquired from the cytoplasm, nucleus and nucleolus of the PAMAM-G5 exposed and corresponding controls. Raman spectral data sets were analysed using Principal Components Analysis (PCA) to determine spectral markers of 
cyto- and geno- toxicity and to observe evolution of spectral markers as a function of time and dose.

\section{Materials and Methods}

\section{Cell Culture and Reagents}

Adenocarcinomic human alveolar basal epithelial cells, A549 (CCL-185TM), was obtained from American Type Culture Collection (ATCC) and used as model cell line to determine Raman spectral markers of cyto- and geno- toxicity upon a toxicant exposure. Dulbecco's Modified Eagle's Medium Nutrient Mixture F-12 HAM (DMEM-F12) was purchased from Sigma-Aldrich (Ireland) and cells were cultured in DMEM-F12 supplemented with $2 \mathrm{mM} \mathrm{L-}$ glutamine and $10 \%$ foetal bovine serum (FBS) at $37{ }^{\circ} \mathrm{C}$ in $5 \% \mathrm{CO}_{2}$ humidified incubator. Cells were sub-cultured when the level of confluency reach to $60 \%-70 \%$, which was approximately 3 to 4 days.

\section{Preparation of Dendrimer Solutions}

Generation 5-polyamidoamine (PAMAM-G5) dendrimers (664049) are used as model dendritic nanoparticles throughout the study, due to their well-known toxicity and commercial availability and they were purchased from Sigma-Aldrich (Ireland). The working solutions of the PAMAM dendrimers were freshly prepared from the stock solutions (initial stock concentration: $1.7 \mathrm{mM})$ in pre-warmed $\left(37^{\circ} \mathrm{C}\right) 5 \%$ FBS and $2 \mathrm{mM}$ L-glutamine supplemented DMEM-F12 medium. The size of the dendrimers is provided as $5.4 \mathrm{~nm}$ by the manufacturer. ${ }^{26}$ The PAMAM dendrimers were also characterised in DMEM-F12 medium by Mukherjee et al. previously using Dynamic light scattering (DLS) and the diameter of the dendrimers are reported to be $6.1 \pm 0.2 \mathrm{~nm}^{20}$ 
Cytotoxicity Evaluation and Calculation of Half-Maximal Effective Concentration $\left(\mathbf{E C}_{50}\right)$

In order to get a general perspective of the toxicity of the PAMAM dendrimers to A549 cells and to determine the concentrations that will be used throughout the Raman microspectroscopy studies, Alamar Blue (AB) and (3-(4, 5-dimethylthiazol-2-yl)-2, 5diphenyltetrazolium bromide (MTT) assays were carried out and they were purchased from Biosciences Ltd. (Ireland) and Sigma-Aldrich (Ireland), respectively. Both AB and MTT assays are conducted on the same 96-well plates. Cells were seeded in 96-well plates with densities of $1 \times 10^{5}, 5 \times 10^{4}$ and $3 \times 10^{4}$ cell $/ \mathrm{mL}$ for 24,48 and $72 \mathrm{~h}$, respectively and plates were kept in $5 \% \mathrm{CO}_{2}$ at $37{ }^{\circ} \mathrm{C}$ for $24 \mathrm{~h}$ for initial attachment and growth. After $24 \mathrm{~h}$ incubation, cell medium was discarded and cells were washed with pre-warmed $\left(37^{\circ} \mathrm{C}\right) \mathrm{PBS}$, twice. Untreated A549 cells were used as negative control, whereas cells exposed to $10 \%$ Dimethyl sulfoxide (DMSO) were used as positive control. In each 96-well plate, 6 replicates of controls and samples with PAMAM exposures were prepared and 3 independent experiments were carried out to determine toxicity. PAMAM solutions were freshly prepared prior to the experiment from its stock, over a concentration range from 5.0 to $0.04 \mu \mathrm{M}$ (8 different concentrations with serial dilutions) in pre-warmed DMEM-F12 medium supplemented with $5 \%$ FBS and $2 \mathrm{mM}$ L-glutamine. The cells were exposed to the prepared solutions of the PAMAM for 24, 48 and $72 \mathrm{~h}$. After test exposures, medium containing the particles was removed and cells were rinsed with PBS three times. $100 \mu 1$ of AB/MTT solution $(5 \%$ [v/v] $\mathrm{AB}$ and $10 \%[\mathrm{v} / \mathrm{v}] \mathrm{MTT})$, prepared in pre-warmed $\left(37^{\circ} \mathrm{C}\right)$ un-supplemented DMEM-F12, were added to the wells and kept at $37{ }^{\circ} \mathrm{C}$ in $5 \% \mathrm{CO}_{2}$ humidified incubator for $3 \mathrm{~h}$. Following $3 \mathrm{~h}$ incubation of the cells with $\mathrm{AB} / \mathrm{MTT}$ solution, fluorescence emission of $\mathrm{AB}$ was measured directly at $595 \mathrm{~nm}$ using a micro plate reader (SpectraMax-M3, Molecular Devices, USA). For MTT measurement, medium containing dye solutions was removed and cells were 
washed with PBS, three times. $100 \mu \mathrm{L}$ of DMSO were added to the wells for dissolution of the formazan product of MTT and plates were kept in a shaker for $10 \mathrm{mins}$ at $200 \mathrm{rpm}$. The MTT absorbance was measured at $570 \mathrm{~nm}$ using the micro plate reader. Data were transferred and analysed in Sigmaplot to determine the half-maximal effective concentration producing a reduction of viability to $50 \%\left(\mathrm{EC}_{50}\right)$. GraphPad was used to predict approximate $\mathrm{EC}_{\mathrm{n}}$ values (reduction of viability to $\mathrm{n} \%$ ) based on the $\mathrm{EC}_{50}$ calculated in SigmaPlot.

\section{Sample preparation for Raman micro-spectroscopy}

For Raman studies, the A549 cells were seeded onto $\mathrm{CaF}_{2}$ discs with a density of 16,000 cells/ per substrate and incubated in 5\% FBS and $2 \mathrm{mM}$ L-glutamine supplemented DMEMF12 for $24 \mathrm{~h}$ at $37{ }^{\circ} \mathrm{C}$ in $5 \% \mathrm{CO}_{2}$. Following the $24 \mathrm{~h}$ initial attachment and growth, cell medium was discarded and cells were rinsed with pre-warmed PBS, twice. The different concentrations of the PAMAM dendrimers were prepared in pre-warmed and supplemented (5\% FBS, 2 mM L-glutamine) DMEM-F12, prior to the experiment. Cells were exposed to the calculated $\mathrm{EC}_{\mathrm{n}}$ values for $24 \mathrm{~h}$ to determine dose dependant responses, whereas cells were exposed to the $\mathrm{EC}_{25}$ from 4 to $72 \mathrm{~h}$ in order to monitor time dependant changes on the spectral markers. Fresh DMEM-F12 with the supplements was used for the control samples. At exposure time end points, the medium containing dendrimers was discarded and cells were washed three times with pre-warmed PBS to remove the non-internalized dendrimers. The samples are fixed using $10 \%$ formalin solution and cells were kept in formalin for 10 mins. After fixation, cells were washed with sterilized $\mathrm{dH}_{2} \mathrm{O}$ and kept in water for Raman measurements.

\section{Raman Microspectroscopy and Data Analysis}

Point spectra from the nucleus, nucleolus and cytoplasm of the 20 individual cells were acquired, for 30 seconds $\mathrm{x} 2$ for each point, using a Horiba Jobin-Yvon LabRAM HR800 
spectrometer equipped with a $785 \mathrm{~nm}$ diode laser, with laser power on the sample of $\sim 70 \mathrm{~mW}$.

Raman spectra of the cells were acquired in water throughout the study with a $100 \mathrm{x}$ immersion objective (LUMPlanF1, Olympus, N.A. 1) producing a spot size of diameter $\sim 1 \mu \mathrm{m}$. Prior to the spectral acquisition, the spectrometer was calibrated to the $520.7 \mathrm{~cm}^{-1}$ line of silicon. A 300 lines per $\mathrm{mm}$ grating, which provides $\sim 1.5 \mathrm{~cm}^{-1}$ per pixel spectral dispersion, and a $100 \mu \mathrm{m}$ confocal pinhole were used and spectra were collected by a 16 bit dynamic range Peltier cooled CCD detector. Spectra were acquired from control and exposed samples in the fingerprint region $\left(400-1800 \mathrm{~cm}^{-1}\right)$. Raman spectral data sets were analysed using Principal Components Analysis (PCA). Pairwise comparison of the control and exposed cells was carried out using data sets, each containing 20 spectra from each cellular compartment. The matrix dimensions of the data sets were kept equal (20 spectra from control and 20 spectra from particle exposed cells) for PCA and mean spectra of the data sets, which are used as input in PCA, are provided in Supplementary Figure S1, S2 and S3 for control, different dose and exposure time, respectively. The data is mean centred as part of the PCA protocol. For all analyses, loadings of the PCA are displayed offset for clarity and the zero ' 0 ' line for each loading, which separates the positive and negative features of the PCA, is indicated with dashed lines. A scaling system based on the ' 0 ' line \pm 0.05 is used for all figures, which allows inter comparison of the spectral marker intensities.

Prior to analysis, data sets were subjected to pre-processing to improve spectral quality. Data was first subjected to mild smoothing using Savitsky-Golay Filter ( $3^{\text {rd }}$ order, 9 points) and background, which is predominantly water in the immersion geometry ${ }^{8,27}$, was subtracted using Classical Least Squares (CLS) analysis. CLSA can be carried out two different ways, by use of a factor analysis algorithm (unsupervised) or by manual input of reference spectra. For background correction, a reference background spectrum, which was obtained from the surface of a $\mathrm{CaF}_{2}$ disc using x100 immersion objective, was subtracted from spectra using 
CLSA. Baseline correction is carried out by applying a rubberband correction in Matlab. Smoothed, background removed and baseline corrected spectra were vector normalised. All pre-processing and the data analysis is performed in Matlab (Mathworks, USA) using inhouse scripts.

\section{Results and Discussion}

\section{Cytotoxicity Evaluation of PAMAM Dendrimers}

The effect of PAMAM-G5 dendrimers on the cellular viability of A549 cells was evaluated by using commercially available and commonly used cytotoxicity assays, AB and MTT. For low doses of the PAMAM dendrimers, the cellular viability as measured using the MTT assay is observed to systematically increase from $100 \%$ to $>120 \%$ compared to controls (Figure 1B). This can be interpreted as an increased mitochondrial activity compared to controls, although a clear toxic response is observed with increasing dose. The mean effective concentration of the cell viability, $\mathrm{EC}_{50}$, was calculated in SigmaPlot by using a four parameter sigmoidal fit and the values are presented in Table 1.

Table 1. Cytotoxicity of PAMAM-G5 on A549 cell line.

$\begin{array}{lcc}\text { PAMAM-G5 [Concentration Range used }(\mu \mathrm{M})] & \text { Time }(\mathrm{h}) & \mathrm{EC}_{50}(\mu \mathrm{M})(\text { Standard Deviation) } \\ \text { Alamar Blue Assay [5-0.3] } & 24 & 1.04( \pm 0.04) \\ & 48 & 0.97( \pm 0.05) \\ \text { MTT Assay [5-0.3] } & 72 & 0.92( \pm 0.04) \\ & 24 & 0.97(0.05) \\ & 48 & 0.84(0.05)\end{array}$


As seen in Figure 1, for all time points, MTT is seen to be more sensitive than AB, consistent with the observations of Mukherjee et al. ${ }^{19}$ and Maher et al. ${ }^{23}$, which can be explained by the mechanism of interaction of PAMAM dendrimers. After PAMAM dendrimers taken up into the cells by endocytosis, they are found to cause endosomal/lysosomal rupture due to the surface amino-groups which provide a high positive charge on the surface..$^{20,23,28,29}$ The endosomal rupture leads the release of the dendrimers into the cytosol and subsequent localisation in the mitochondria. ${ }^{23,30}$ The mechanism results in an early stage ( $\left.4 \mathrm{hrs}\right)$ and late stage $(>12 \mathrm{hrs})$ increase in intracellular reactive oxygen species. ${ }^{31}$ Although the $\mathrm{EC}_{50}$ values determined are similar for AB and MTT, the different trend for the MTT response after $24 \mathrm{~h}$ is consistent with the interaction of the PAMAM dendrimers with the mitochondria of the cells. $^{19,20,23,31}$

(A)

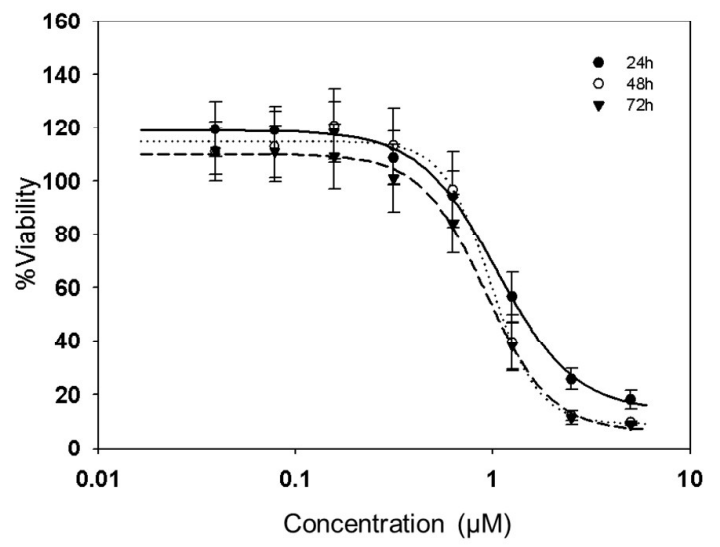

(B)

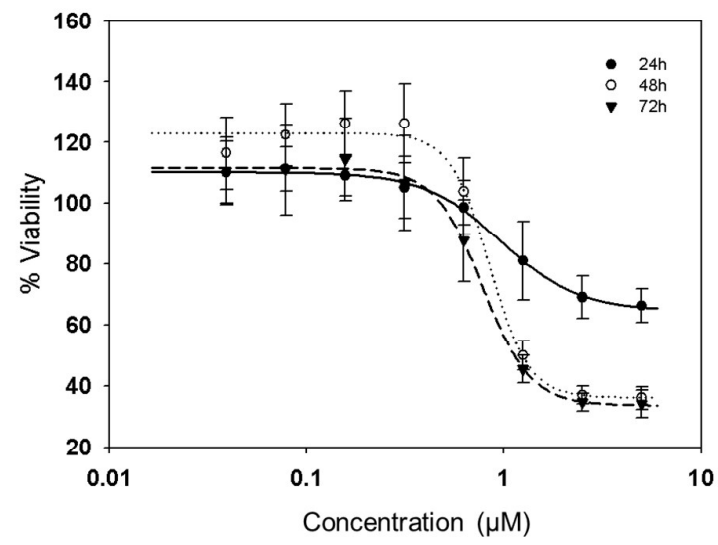


Figure 1. Cytotoxicity of generation 5 polyamidoamine (PAMAM-G5) dendrimers after 24, 48 and $72 \mathrm{~h}$ exposures determined by the Alamar Blue (A) and MTT assays (B). Data are expressed as $\%$ of control mean $\pm \mathrm{SD}$ of three independent experiments.

In order to monitor these trends with Raman microspectroscopy and to identify spectral markers of cyto- and geno- toxicity upon PAMAM-G5 exposure, 20 point spectra were acquired from the cytoplasm, nucleus and nucleolus of PAMAM-G5 exposed cells and their corresponding controls.

\section{Raman Spectral Markers of Cytotoxicity: Cytoplasm}

The effect of different concentrations of PAMAM-G5 dendrimers on the cytoplasm of A549 cells was evaluated by using a concentration range from $\mathrm{EC}_{10}$ to $\mathrm{EC}_{75} . \mathrm{EC}_{\mathrm{n}}$ values are calculated as $1.72( \pm 0.08), 1.04( \pm 0.04), 0.6( \pm 0.03)$ and $0.38( \pm 0.02) \mu \mathrm{M}$ for $\mathrm{EC}_{75}, \mathrm{EC}_{50}$, $\mathrm{EC}_{25}$ and $\mathrm{EC}_{10}$, respectively from the responses determined by the $\mathrm{AB}$ assay obtained after 24 $\mathrm{h}$ exposure and are used to determine dose dependant changes on the spectral markers of cellular responses after $24 \mathrm{~h}$. With increasing dose, significant and progressive changes are observed in the bands corresponding to nucleic acid, protein and lipid structures inside the cytoplasm. Using PCA, for all applied doses, PAMAM-G5 exposed cells clearly separated from their controls according to PC1 (Explained Variance $\sim 69 \%-82 \%$, Supplementary Figure S4) and PAMAM exposed cells scored positively, whereas control cells scored negatively. Therefore, the positive $(\mathrm{PC} 1>0)$ features of the loadings represent the biochemical composition of the particle exposed cells, whereas negative $(\mathrm{PC}<0)$ features represent the control cells. The changes in the biochemical features of the loadings as a function of time and/or dose can be attributed to increases or decreases in composition of specific component of the cell in particle exposed cells compared to the control cells. As seen in Figure 2, the 
most significant changes in the loadings, corresponding to cytoplasm of PAMAM-G5 exposed cells and their controls, are observed up to the $\mathrm{EC}_{50}$ and notably, similar loadings are obtained from the cells which are exposed to $\mathrm{EC}_{50}$ and $\mathrm{EC}_{75}$ concentrations, which can be explained by a reduction in the toxic response rate due to saturation of the cell cytoplasm by the nanoparticles. For sub-lethal concentrations $\left(\mathrm{EC}_{10}\right.$ and $\left.\mathrm{EC}_{25}\right)$, the positive side of the loading is dominated by nucleic acid features at 785 (nucleic acids) and 810 (RNA) $\mathrm{cm}^{-1}{ }^{32-}$ ${ }^{34}$ which have been previously identified as indicators of oxidative stress, resulting in accumulation of the noncoding RNAs or changes on the cytoplasmic RNA. ${ }^{14,}{ }^{15}$ When the exposure dose is increased to $\mathrm{EC}_{50}$ and $\mathrm{EC}_{75}$, the relative intensity of the band at $785 \mathrm{~cm}^{-1}$ is observed to decrease, while the band at $810 \mathrm{~cm}^{-1}$ remains almost the same over the dose range, with a slight increase from $\mathrm{EC}_{10}$ to $\mathrm{EC}_{25}$. Similar to the band at $785 \mathrm{~cm}^{-1}$, a progressive decrease of the intensity of the nucleic acid bands at $669 \mathrm{~cm}^{-1}$ (T and G (DNA/RNA) and $1098 \mathrm{~cm}^{-1}$ (Phosphodioxy $\left(\mathrm{PO}_{2}^{-}\right)$groups) is observed with increasing PAMAM-G5 concentration. $^{32,34}$

Although the Amide I region (1600-1700 $\left.\mathrm{cm}^{-1}\right)^{32-34}$ does not show a significant change with increasing dose over the range studied, an increase in protein composition of the exposed cells is observed compared to the control cells. The protein bands at 1003 (Phenlyalanine, Phe), 1556 (Tryptophan, Trp) and 1573 (Trp) $\mathrm{cm}^{-1}$ are also observed in the positive features of the loadings. ${ }^{32-34}$ Significant changes are also observed for the bands related to lipid composition of the cell. In the positive features of the loadings, the intensity of the band at $1125 \mathrm{~cm}^{-1}$ (skeletal of acyl backbone in lipid) ${ }^{34}$ has reduced significantly when the exposure dose reached $\mathrm{EC}_{50}$. In the negative features of the loadings, lipid based structures are observed to be dominant, which indicates the loss of lipid in PAMAM exposed cells. A progressive increase is also observed in the intensity of the band at $702 \mathrm{~cm}^{-1}$ in the negative features of the loading, which indicates a decrease in cholesterol in PAMAM exposed cells 
with increasing concentration. ${ }^{34}$ Cholesterol is known to be an abundant sterol, especially in the cellular membrane of mammalian cells and is required for viability and cell proliferation. Damage to the cholesterol in the cytoplasm can be attributed to damage to the membrane composition due to the highly positive surface charge. PAMAM dendrimers, as cationic nanoparticles, have been shown to reduce membrane integrity via formation of holes in lipid bilayers which results in membrane erosion. ${ }^{35,36}$ Moreover, the band at $715 \mathrm{~cm}^{-1}$ (membrane phospholipid head) as well as other lipid features at 1299 and $1438 \mathrm{~cm}^{-1}$, are observed to contribute negatively, also consistent with damage to membrane structures for particle exposed cells. $^{32-34}$

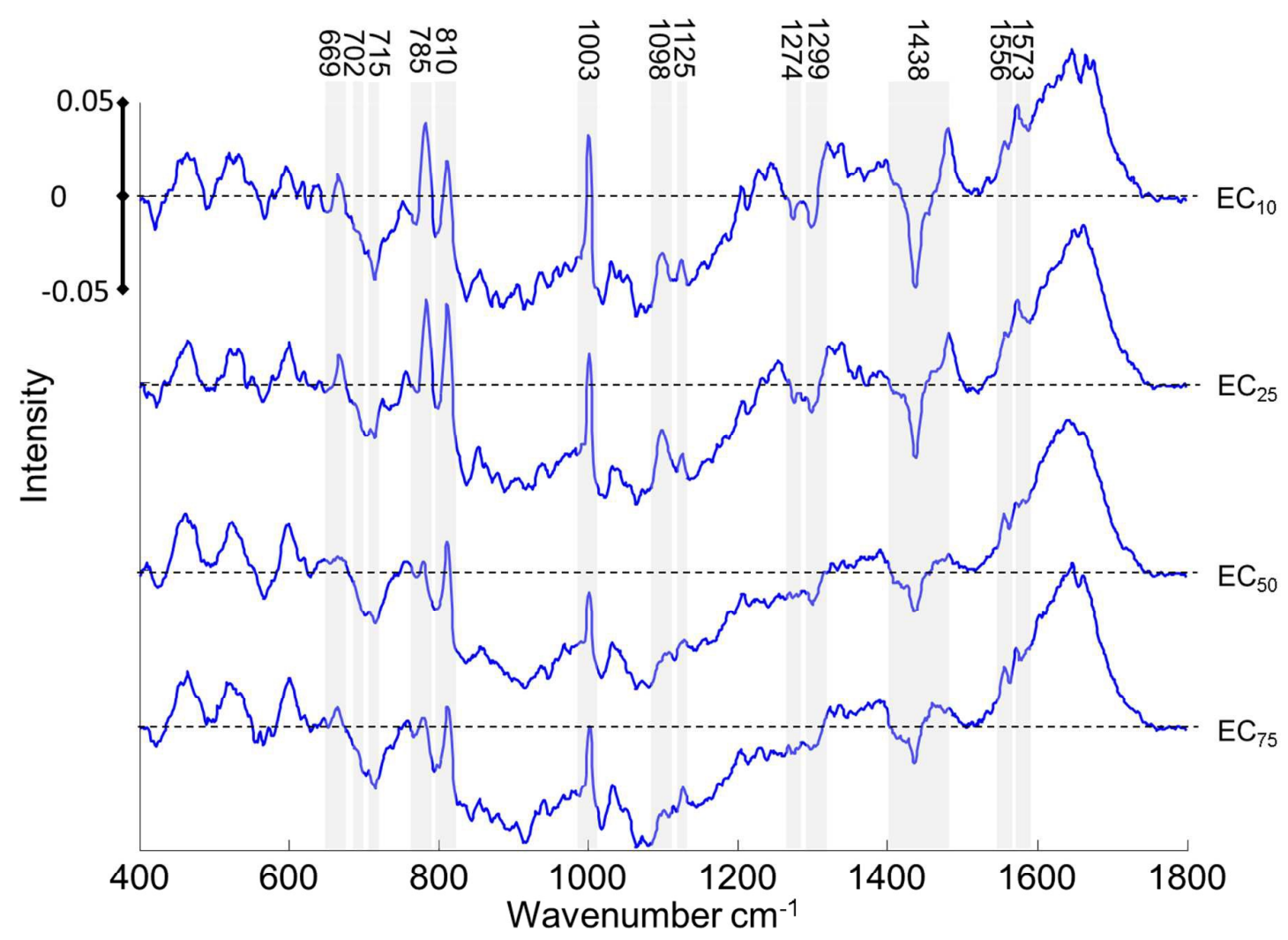

Figure 2. Loadings of $\mathrm{PC} 1$ for pairwise analysis of cytoplasm of exposed cells $\left(\mathrm{EC}_{\mathrm{n}}\right)$ and corresponding control after $24 \mathrm{~h}$ PAMAM-G5 exposure. The negative side of the loading 
represents the spectral features of control, whereas positive side represents the cells exposed to PAMAM-G5. Loadings are offset for clarity and zero ' 0 ' line for each dose is indicated with black dashes. The progressive changes in the loadings are indicated with grey highlights and corresponding band assignments are provided on top of the highlights.

The changes in the spectral markers associated with toxic events in the cytoplasm were also evaluated as a function of exposure time. The sub-lethal dose $\left(\mathrm{EC}_{25}\right.$, determined by $\mathrm{AB}$ assay after $24 \mathrm{~h}$ ) of PAMAM-G5 was used to observe progressive changes from 4 to $72 \mathrm{~h}$. The calculated $\mathrm{EC}_{25}$ values are found to be similar for each time point from 24-72 $\mathrm{h}$, and therefore, the $\mathrm{EC}_{25}$ for $24 \mathrm{~h}$ is used for time dependant evaluation of spectral markers.

The scatter plots of the PCA of the cytoplasm of particle exposed cells and corresponding controls are provided in Supplementary Figure S5. The control cells clearly differentiated from PAMAM-G5 exposed cells according to PC1, with an explained variance ranging from $76 \%-91 \%$. For $4 \mathrm{~h}$ exposure, the loading of PC1 dominated by positive features which show the higher presence of cytoplasmic RNAs, proteins and lipids in PAMAM-G5 exposed cells compared to the control cells (Figure 3). The doublet of peaks at 785 and $810 \mathrm{~cm}^{-1}$ is again observed to be one of the prominent evolving features in the loadings. A continuous increase is observed in the intensity of the band at $785 \mathrm{~cm}^{-1}$ with extended exposure time. An increase is observed in the intensity of the band at $810 \mathrm{~cm}^{-1}$ up to $24 \mathrm{~h}$, followed by a decrease after 48 $\mathrm{h}$. The band becomes a negative feature of the loading after $72 \mathrm{~h}$, which can be attributed to a loss of long-noncoding RNAs and secondary changes to the cytoplasmic RNA in the cytoplasm of PAMAM-G5 exposed cells with extended exposure times. The decrease of the band at $600 \mathrm{~cm}^{-1}$ (nucleotide conformation) ${ }^{34}$ can also be used as an indicator of RNA damage after $48 \mathrm{~h}$. The next most prominent change after the bands at 785 and $810 \mathrm{~cm}^{-1}$ is observed in the band at $1438 \mathrm{~cm}^{-1}$. The band at $1438 \mathrm{~cm}^{-1}$, which can be attributed to $\mathrm{CH}_{2}$ and 
$\mathrm{CH}_{3}$ deformation vibrations of lipids, ${ }^{34}$ indicates the total lipid saturation and damage in lipid structures, observed as a negative feature of loading 1 of PCA after $4 \mathrm{~h}$. The other lipid bands in the fingerprint region of the spectra, 702 (cholesterol) and 715 (membrane phospholipids head) $\mathrm{cm}^{-1}$, are also observed as negative features of the loadings for exposure times over $8 \mathrm{~h}$ and a progressive increase in the intensity of the bands is observed with extended exposure time. The increase in the intensity of these negative features of the loading can be attributed to higher membrane stability of the control cells compared to PAMAM exposed cells. The different progression of the band at $1438 \mathrm{~cm}^{-1}$ (lipid) between different doses (a decrease on the intensity with increasing dose) and exposure times (an increase on the intensity with extended exposure time), can be attributed to different lipotoxic effects of PAMAM-G5 dendrimers in acute versus long term exposures. The bands at 1274 and 1299 $\mathrm{cm}^{-1}$ are observed as negative features of the loading for all exposure times, with increasing intensities, and can be attributed to distortion in Amide II structures of the proteins and also damage in lipids in PAMAM-G5 exposed cells. 


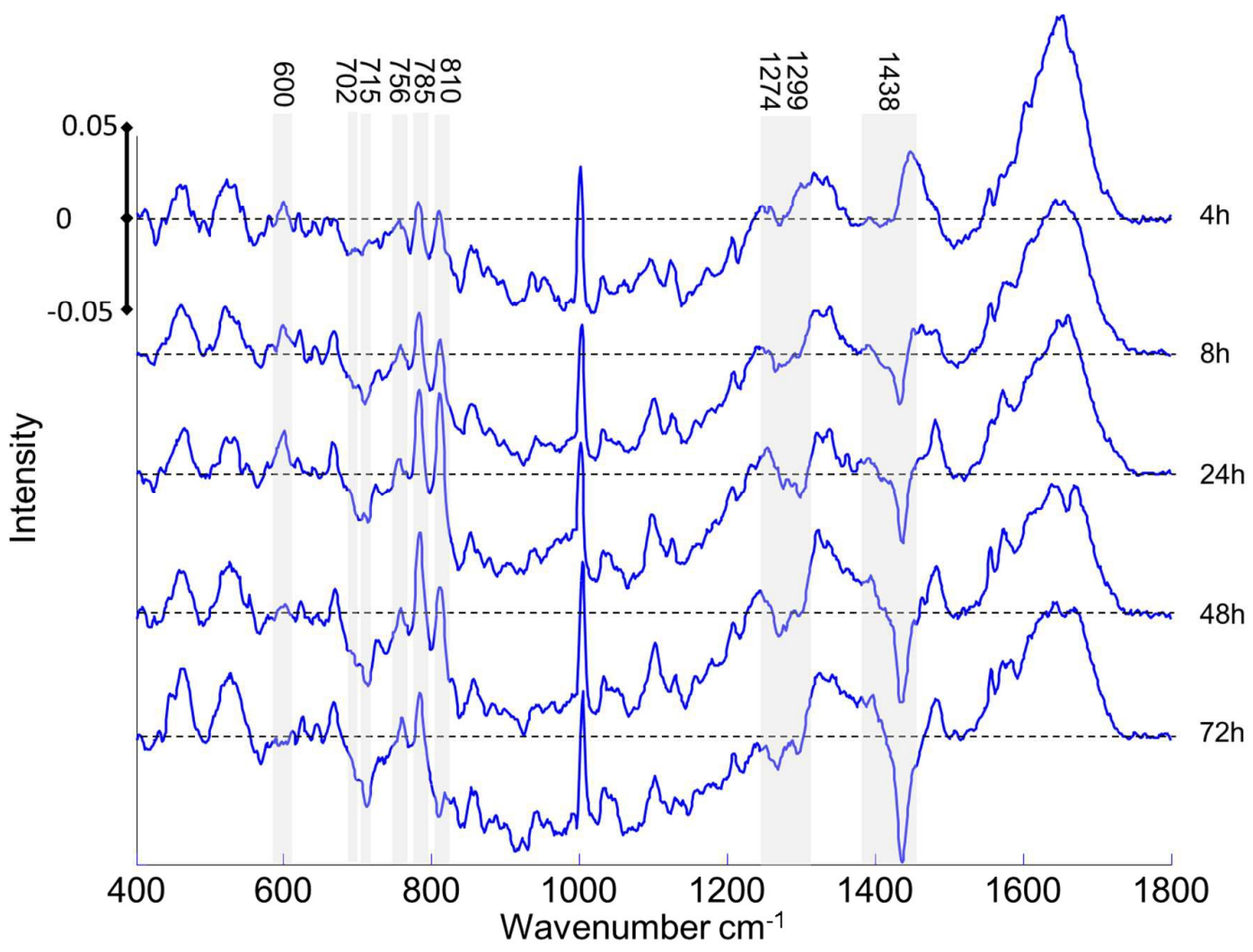

Figure 3. Loadings of $\mathrm{PC} 1$ for pairwise analysis of cytoplasm of exposed cells and corresponding control from 4 to $72 \mathrm{~h}$ PAMAM-G5 $\left(\mathrm{EC}_{25}\right)$ exposure. The negative side of the loading represents the spectral features of control, whereas positive side represents the cells exposed to PAMAM-G5. Loadings are offset for clarity and the zero ' 0 ' line for each dose is indicated with black dashes. The progressive changes in the loadings are indicated with grey highlights and corresponding band assignments are provided on top of the highlights.

The doublet peak at 785 and $810 \mathrm{~cm}^{-1}$ has previously been identified as a spectral marker of oxidative stress in aminated polystyrene $\left(\mathrm{PS}-\mathrm{NH}_{2}\right)$ exposed cells, resulting in cytoplasmic RNA alterations and damage in the cytoplasm. ${ }^{14,}{ }^{15}$ The consistency of the doublet peak following PAMAM exposure provides a validation of the Raman spectral markers for cellular toxic events such as ROS formation. Notably, however, the final localisation of $\mathrm{PS}-\mathrm{NH}_{2}$ has 
been observed to be in the Endoplasmic Reticulum or Golgi apparatus, ${ }^{12}$ and no significant spectral changes were observed in the nuclear regions of the exposed cells. ${ }^{14}$

\section{Raman Spectral Markers of Geno-Toxicity: Nucleus and Nucleolus}

Although the effect of the PAMAM dendrimers on the genetic material of mammalian cells has been studied, the mechanism leading to the effect still remains unknown due to the size and non-flourescent nature of the PAMAM dendrimers. The use of the labels with PAMAM dendrimers can also change the structure related cell response due to oversize of the used labels compared to the original size of the PAMAM dendrimers. PAMAM dendrimers have been shown to induce DNA damage by using the Comet assay in a study of Naha et al., ${ }^{21}$ although the mechanism leading to the damage remained unclear. The effect of the oxidative stress and formation of reactive oxygen species have been shown to induce DNA damage in various ways, such as 8-hydroxy-2'-deoxyguanosine (8-OHdG) formation, single or double strand DNA breaks, chromatid exchanges and mutations. ${ }^{21,37,38}$

Raman microspectroscopy can provide insights into the genetic material-PAMAM interaction by exploring changes of the spectral signatures of the genetic material (DNA, RNA). The changes in the nucleus and nucleolus upon PAMAM exposure were monitored and spectral markers of the genotoxic events identified. With increasing exposure times, the nucleus of A549 cells exposed to PAMAM-G5 clearly differentiated from their controls according to PC1, with explained variance of 77\%-91\% (Supplementary Figure S6). The loadings of the PC, for all exposure times, are dominated by features which indicate the presence of biomolecular alterations in particle exposed cells compared to their controls (Figure 4). The main changes in the loadings from 4 to $72 \mathrm{~h}$ are observed to be in the range between $700-830$ $\mathrm{cm}^{-1}$ (nucleic acid region) and the band at $1556 \mathrm{~cm}^{-1}$ (Tryptophan, Trp). 


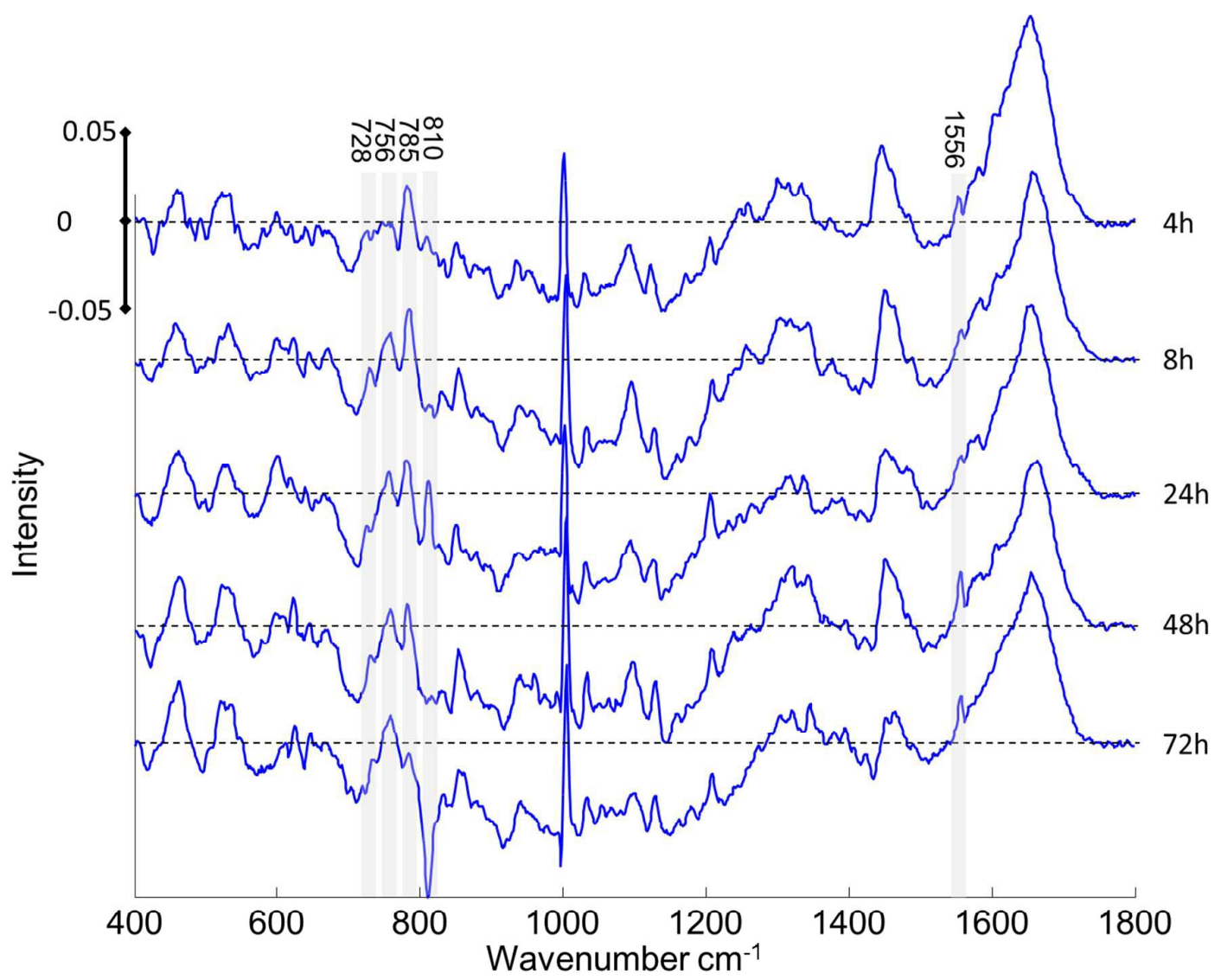

Figure 4. Loadings of PC1 for pairwise analysis of nucleus of exposed cells and corresponding control from 4 to $72 \mathrm{~h}$ PAMAM-G5 $\left(\mathrm{EC}_{25}\right)$ exposure. The negative side of the loading represents the spectral features of control, whereas positive side represents the cells exposed to PAMAM-G5. Loadings are offset for clarity and the zero ' 0 ' line for each dose is indicated with black dashes. The progressive changes in the loadings are indicated with grey highlights and corresponding band assignments are provided on top of the highlights.

As a function of exposure time, there are slight changes observed in the intensity of the band at $785 \mathrm{~cm}^{-1}$ (DNA/RNA), whereas the changes are more pronounced for the intensity of the band at $810 \mathrm{~cm}^{-1}$ (RNA) (Supplementary Figure S7 for plotted band intensities). The band at $785 \mathrm{~cm}^{-1}$ is known to be a spectral marker for uracil $(\mathrm{U})$, thymine $(\mathrm{T})$, cytosine $(\mathrm{C})$ ring 
breathing modes in DNA and RNA, whereas the $810 \mathrm{~cm}^{-1}$ is more specific to RNA O-P-O band stretching. ${ }^{34}$ Therefore, the slight changes in the intensity of the bands at $785 \mathrm{~cm}^{-1}$ can be indicative of changes in local conformation, rather than to chemical changes to the nucleobases in the nucleic acids. However, the intensity of the band at $810 \mathrm{~cm}^{-1}$ showed a significant increase between 8 and $24 \mathrm{~h}$, followed by a decrease until $72 \mathrm{~h}$ and the band becomes a negative feature of the loading, which shows higher RNA content in nucleus of control cells compared to PAMAM exposed cells. The increase up to $24 \mathrm{~h}$ can be attributed to the effect of oxidative stress on RNA content in the nuclear region, whereas reduction after $24 \mathrm{~h}$ and damage of the RNA in the nuclear region can be related to genotoxicity of the PAMAM dendrimers.

The other characteristic bands in the loadings of the nucleus corresponding to the PAMAMG5 exposed cells and their controls are observed to be the bands at 728 (Adenine, DNA) and 756 (Trp and/or DNA, C5-H (cytosine)) $\mathrm{cm}^{-1}$. With extended exposure time, the intensities of the bands are observed to increase, with a more significant increase at $756 \mathrm{~cm}^{-1}$ compared to $728 \mathrm{~cm}^{-1}$ Figure 5A). When different doses of the PAMAM-G5 are exposed to the A549 cells, the band at $728 \mathrm{~cm}^{-1}$ does not show a significant change, whereas the band at $756 \mathrm{~cm}^{-1}$ is significantly changed for the doses over $\mathrm{EC}_{25}$ concentration (Figure $5 \mathrm{~B}$ ). The increase in the band at $756 \mathrm{~cm}^{-1}$ along with the changes in the $830 \mathrm{~cm}^{-1}$ band $\left(\mathrm{PO}_{2}{ }^{-}\right.$stretch of nucleic acids) can be attributed to significant changes in DNA over the extended exposure times (Figure 4). Similarly, when the exposure dose is changed between $\mathrm{EC}_{25}$ and $\mathrm{EC}_{50}$, the band at $830 \mathrm{~cm}^{-1}$ disappears (Figure 5C). The band at $1220 \mathrm{~cm}^{-1}$ also shows the changes in the phosphate backbone $\left(\mathrm{PO}_{2}{ }^{-}\right)$. In this case, the interaction of PAMAM dendrimers with nuclear material can be related to DNA modifications and cell death. 
(A)

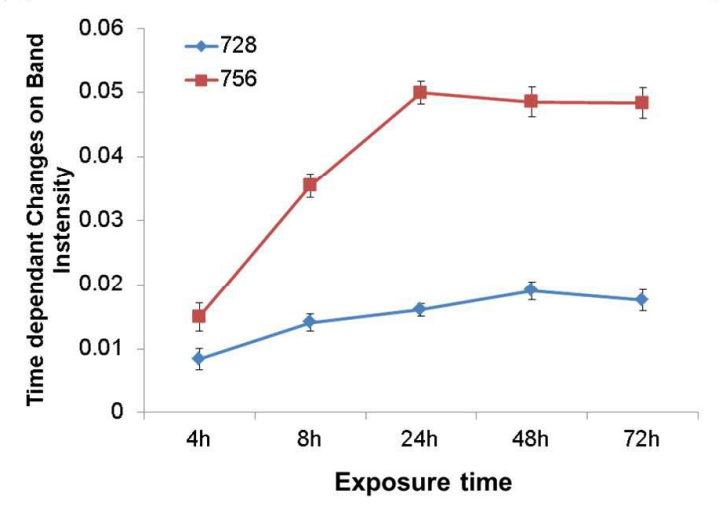

(B)

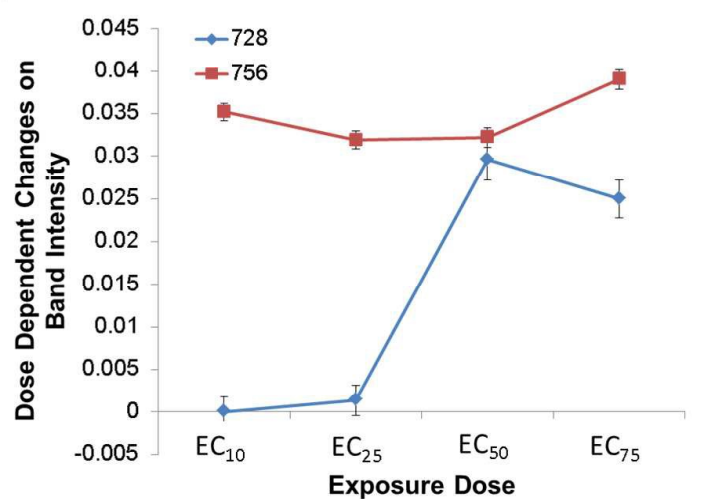

(C)

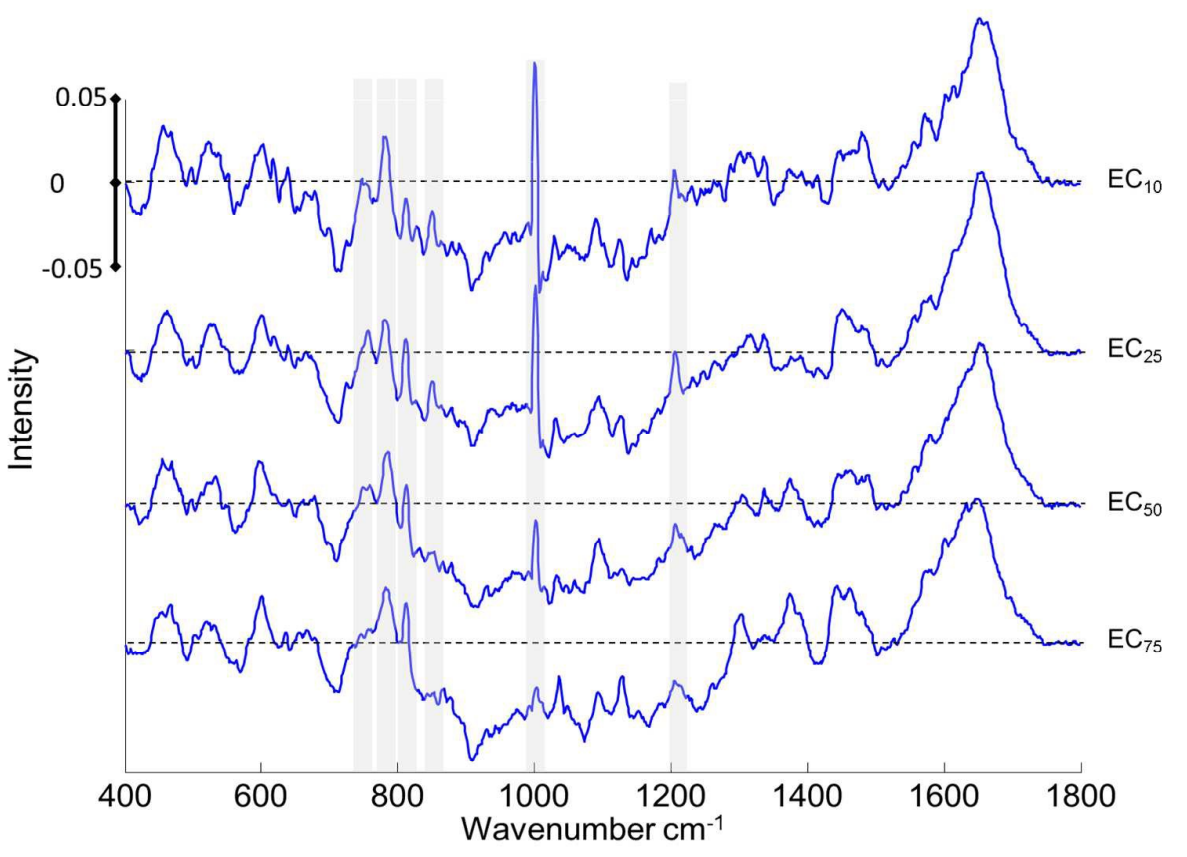

Figure 5. A) Comparison of time dependant changes on the band intensities of 728 and 756 $\mathrm{cm}^{-1}$ bands calculated from pairwise PCA of nucleus of exposed cells and corresponding control, B) Comparison of dose dependant changes on the band intensities of 728 and 756 $\mathrm{cm}^{-1}$ bands calculated from pairwise PCA of nucleus of PAMAM exposed cells and corresponding control, in $\mathrm{A}$ and $\mathrm{B}$ error bars indicate $\pm \mathrm{SD}$ of the band intensities, C) Loadings of PC1 for pairwise analysis of nucleus of exposed cells and corresponding control after 24h PAMAM-G5 exposure. The negative side of the loading represents the spectral features of control, whereas positive side represents the cells exposed to PAMAM-G5. Loadings are offset for clarity and zero ' 0 ' line is indicated with black dashes. The 
progressive changes in the loadings are indicated with grey highlights and corresponding band assignments are provided on top of the highlights.

When the intensities of the 785 and $810 \mathrm{~cm}^{-1}$ bands are calculated, they are observed to increase with increasing exposure dose and the changes between $\mathrm{EC}_{10}-\mathrm{EC}_{25}$ and $\mathrm{EC}_{50}-\mathrm{EC}_{75}$ concentrations are observed to be more pronounced compared to $\mathrm{EC}_{25}-\mathrm{EC}_{50}$ differences (Supplementary Figure S8). Although it is extremely challenging to determine localisation of PAMAM dendrimer in the nucleus due to the non-fluorescent nature of the dendrimers, and significant increase in the particle size and physicochemical properties upon fluorescent labelling, Raman microspectroscopy can be used to identify PAMAM-G5 presence in the nucleus and nucleolus. PAMAM-G5 dendrimers can pass the nuclear membrane and interact with nuclear material due to their highly positive surface and small size (measured diameter of G5 is $5.4 \mathrm{~nm}$, size in medium $\sim 6.5 \mathrm{~nm}) .{ }^{39}$ When the changes in the band at $810 \mathrm{~cm}^{-1}$ over time and dose for the nuclear region (nucleus and nucleolus) are considered, the interaction of the PAMAM-G5 with nuclear material can be seen as more a pronounced PAMAM-RNA interaction compared to PAMAM-DNA interaction. When the first loading of the PCA is considered for the cells exposed to the different doses of the PAMAM-G5 dendrimers, the spectra of cytoplasm and nucleus do not show a significant change until the concentration is increased to the $\mathrm{EC}_{50}$. A significant change is observed for the loading of the cell exposed to $\mathrm{EC}_{75}$ of PAMAM dendrimers versus corresponding controls, and the features of the loading become completely different compared to previous doses (Figure 6A). Atomic simulations of dendrimer-nucleic acid interactions have been conducted by Nandy et al. and the study showed the formation of stable DNA and siRNA complexes with PAMAM dendrimers at a physiological $\mathrm{pH}$ based on electrostatic interaction. ${ }^{40}$ The strong binding affinity of PAMAM dendrimers to the RNA has also been shown in computational and experimental designs by 
Pavan et al. ${ }^{41}$ The dose and time dependent changes on the nucleolus of the A549 cells upon PAMAM-G5 exposure are also evaluated in order to clarify mechanism of action of PAMAM-G5 dendrimers with RNA. The scatter plots of PCA of nucleolus of PAMAM-G5 exposed A549 cells and corresponding controls are provided in Supplementary Figure S9 and S10 for dose dependent and time dependent responses, respectively. For both cases, PAMAM-G5 exposed cells and corresponding controls are clearly separated from each other with calculated high explained variance at different time points (Explained variance $\sim 70 \%$ $90 \%$ ) compared to different doses (Explained variance $\sim 40 \%-78 \%$ ). As seen in Figure $6 \mathrm{~A}$ and $\mathrm{B}$, the most dominant features of the loadings with significant changes as a function of both time and dose are determined to be the bands at 728, 756, 785, 810 and $830 \mathrm{~cm}^{-1}$. When the exposure dose is increased from $\mathrm{EC}_{25}$ to $\mathrm{EC}_{75}$, the intensity of the bands at 785,810 and $830 \mathrm{~cm}^{-1}$ are decreased, whereas an increase is observed for the bands at 728 and $756 \mathrm{~cm}^{-1}$ and loadings are dominated by the features in the positive side which corresponds to PAMAM-G5 exposed cells. When the exposure dose reached $\mathrm{EC}_{75}$, significant changes are observed in the loadings. In addition to the changes in the bands at $728,756,810$ and $830 \mathrm{~cm}^{-}$ ${ }^{1}$, changes in the bands at $1033\left(\mathrm{C}-\mathrm{H}\right.$ in plane Phe), $1095\left(\mathrm{PO}_{2}{ }^{-}\right.$str.), 1128 (C-N str. of proteins), $1209\left(\mathrm{C}-\mathrm{C}_{6} \mathrm{H}_{5}\right.$ str. Phe, Trp), $1301\left(\mathrm{CH}_{2}\right.$ twist of lipids), 1369 (Guanine), 1438 (lipids), 1460 ( $\mathrm{N}_{2}-\mathrm{H}$ (cytosine), $\mathrm{C}_{4}-\mathrm{C}_{5}$ (cytosine)), 1600 (Amide I) and 1654 (Amide I) $\mathrm{cm}^{-}$ ${ }^{1,32-34}$ observed as positive features of the loading, are consistent with dramatic changes in protein and nucleic acid content of the nucleus. Recent studies have shown the effect of the nanomaterials on epigenetic modifications such as DNA methylation, post-translational modifications and formation of non-coding RNAs. ${ }^{42-44}$ The changes in the DNA and protein bands can be attributed to modifications in DNA such as chemical modifications on the C5 position of cytosines. $^{42}$ 
The study demonstrates that Raman microspectroscopy can be employed to monitor signatures of the toxic responses of cells to nanoparticle exposures. Although the spectroscopic signatures of the initiating events can consistently be identified, the subsequent evolution of the toxic response is a complex cascade of events, ${ }^{24}$ and this, coupled with the limited number of dose and time points, mean that more sophisticated by linear data-mining approaches to data analysis, such as Partial Least Squares Regression are not suitable. However, emerging, more rapid spectroscopic screening technologies will afford more continuous and even real-time monitoring of such toxicological response pathways, which ultimately may be analysed using more sophisticated data mining techniques such as Multivariate Curve Resolution Alternating Least Squares. 

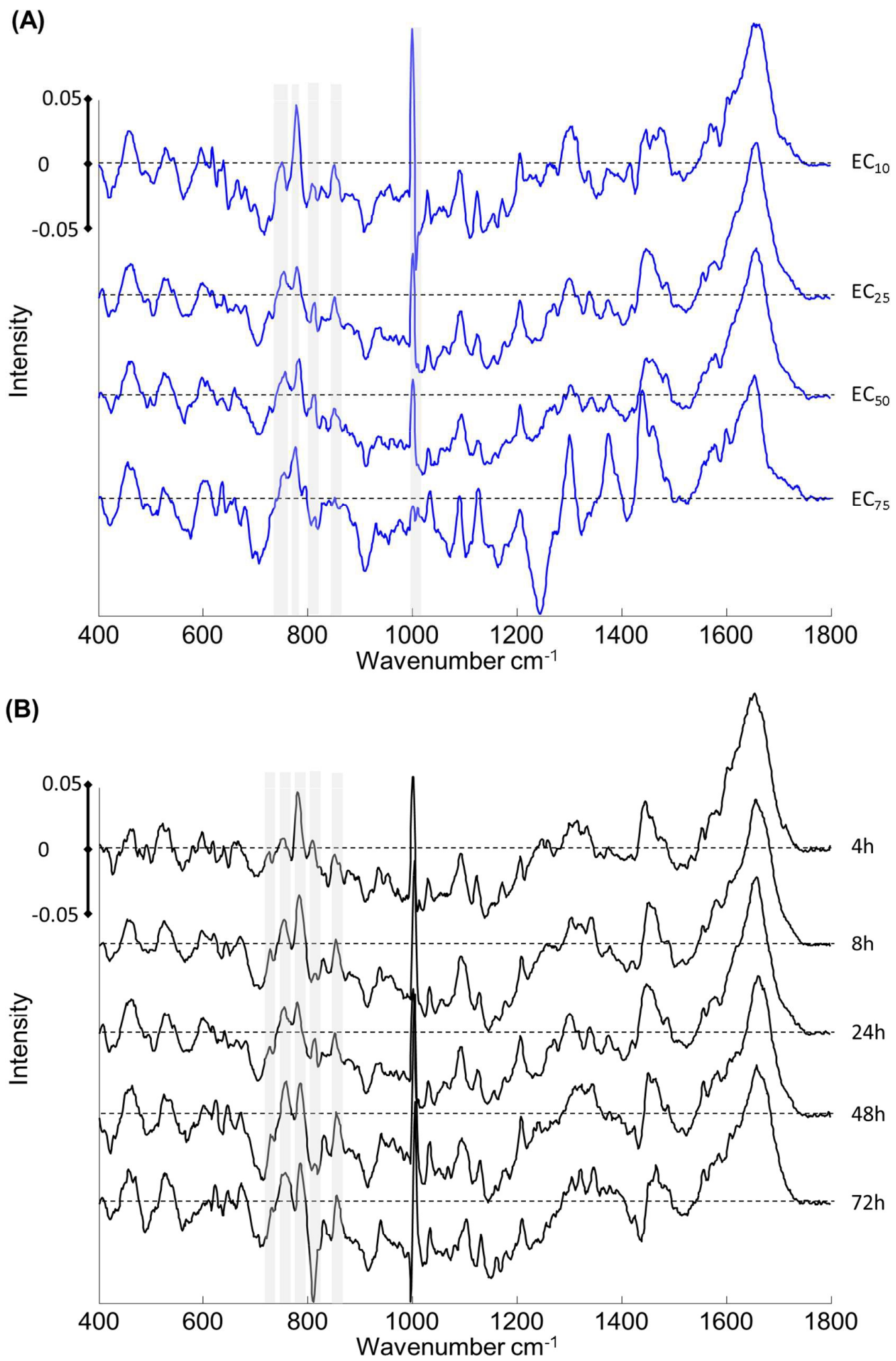

Figure 6. A) Loadings of PC1 for pairwise analysis of nucleolus of exposed cells and corresponding control after 24h PAMAM-G5 exposure. B) Loadings of PC1 for pairwise 
analysis of cytoplasm of exposed cells and corresponding control from 4 to $72 \mathrm{~h}$ PAMAMG5 exposure. The negative side of the loading represents the spectral features of control, whereas positive side represents the cells exposed to PAMAM-G5. Loadings are offset for clarity and zero ' 0 ' line is indicated with black dashes. The progressive changes in the loadings are indicated with grey highlights and corresponding band assignments are provided on top of the highlights.

\section{Conclusion}

The analysis of a broad range of nanomaterials, in a rapid and multi-parametric fashion, is of significant importance, to identify mechanism of action and possible adverse health and environmental effects. In this study, the potential of Raman microspectroscopy has been shown to identify cyto- and geno- toxic responses in cell upon a toxicant exposure. In PAMAM-G5 exposed cells, ROS formation and oxidative stress has been established as the principal toxic mechanism and is associated a significant impact on mitochondria. The increased levels of the ROS are monitored by evolution of the Raman bands at 785 and 810 $\mathrm{cm}^{-1}$. The secondary impact of PAMAM-G5 dendrimers inside the cell is observed as a lipotoxic effect, which is identified by the spectral marker at $1438 \mathrm{~cm}^{-1}$. When the spectral markers of the cytotoxicity of PAMAM-G5 and $\mathrm{PS}-\mathrm{NH}_{2}$ exposed cells, from a previous study, are considered, a high degree of consistency of the Raman spectral markers is observed. The differences between the spectral markers, especially those in the region above $1000 \mathrm{~cm}^{-1}$, for PAMAM-G5 and PS-NH 2 exposed cells can be attributed to different cell death mechanisms which can be investigated further. The study further shows the applicability of Raman microspectroscopy to determine spectral markers of the genotoxicity and possible PAMAM-DNA/RNA interactions based on the changes of nucleic acid bands in 
the range from 750 to $830 \mathrm{~cm}^{-1}$. The PAMAM-RNA interaction is observed to be more pronounced compared to the DNA interaction, which can be an indicator of localisation of the PAMAM in the nucleolus. The spectral markers of the post-translational modifications and corresponding biochemical changes are identified, and can be used to characterise biochemical consequences of biomolecular modifications such as changes in Trp and cytosine $\mathrm{C} 5-\mathrm{H}$.

\section{Acknowledgments}

This work was supported by Science Foundation Ireland Principle Investigator Award 11/PI/1108.

\section{References}

1. W. T. Godbey, K. K. Wu and A. G. Mikos, Proceedings of the National Academy of Sciences of the United States of America, 1999, 96, 5177-5181.

2. G. Tosi, B. Bortot, B. Ruozi, D. Dolcetta, M. A. Vandelli, F. Forni and G. M. Severini, Curr Med Chem, 2013, 20, 2212-2225.

3. I. Brigger, C. Dubernet and P. Couvreur, Advanced Drug Delivery Reviews, 2012, 64, 24-36.

4. G. Oberdörster, A. Maynard, K. Donaldson, V. Castranova, J. Fitzpatrick, K. Ausman, J. Carter, B. Karn, W. Kreyling, D. Lai, S. Olin, N. Monteiro-Riviere, D. Warheit and H. Yang, Particle and Fibre Toxicology, 2005, 2, 8.

5. K. Donaldson, V. Stone, C. L. Tran, W. Kreyling and P. J. Borm, in Occup Environ Med, England, 2004, vol. 61, pp. 727-728.

6. U. Liebel and W. Link, Biotechnol J, 2007, 2, 938-940. 
7. A. G. Walton, M. J. Deveney and J. L. Koenig, Calcified Tissue Research, 1970, 6, 162-167.

8. F. Bonnier, F. Petitjean, M. J. Baker and H. J. Byrne, Journal of Biophotonics, 2014, 7, 167-179.

9. F. Bonnier, A. Mehmood, P. Knief, A. D. Meade, W. Hornebeck, H. Lambkin, K. Flynn, V. McDonagh, C. Healy, T. C. Lee, F. M. Lyng and H. J. Byrne, Journal of Raman Spectroscopy, 2011, 42, 888-896.

10. G. J. P. a. J. Breve, in "Biomedical Applications of Spectroscopy”, John Wiley and Sons, New York, 1996, vol. 25.

11. J. Dorney, F. Bonnier, A. Garcia, A. Casey, G. Chambers and H. J. Byrne, Analyst, 2012, 137, 1111-1119.

12. E. Efeoglu, M. Keating, J. McIntyre, A. Casey and H. J. Byrne, Analytical Methods, 2015, 7, 10000-10017.

13. M. E. Keating, F. Bonnier and H. J. Byrne, Analyst, 2012, 137, 5792-5802.

14. E. Efeoglu, A. Casey and H. J. Byrne, Analyst, 2016, 141, 5417-5431.

15. E. Efeoglu, A. Casey, H. J. Byrne, Analyst, Submitted.

16. L. J. Twyman, A. E. Beezer, R. Esfand, M. J. Hardy and J. C. Mitchell, Tetrahedron Letters, 1999, 40, 1743-1746.

17. M. W. Bourne, L. Margerun, N. Hylton, B. Campion, J.-J. Lai, N. Derugin and C. B. Higgins, Journal of Magnetic Resonance Imaging, 1996, 6, 305-310.

18. J. Zhou, J. Wu, N. Hafdi, J. P. Behr, P. Erbacher and L. Peng, Chem Commun (Camb), 2006, 2362-2364.

19. S. P. Mukherjee and H. J. Byrne, Nanomedicine, 2013, 9, 202-211.

20. S. P. Mukherjee, M. Davoren and H. J. Byrne, Toxicol In Vitro, 2010, 24, 169-177.

21. P. C. Naha and H. J. Byrne, Aquat Toxicol, 2013, 132-133, 61-72. 
22. P. C. Naha, M. Davoren, F. M. Lyng and H. J. Byrne, Toxicology and Applied Pharmacology, 2010, 246, 91-99.

23. M. A. Maher and H. J. Byrne, Anal Bioanal Chem, 2016, 408, 5295-5307.

24. M. A. Maher, P. C. Naha, S. P. Mukherjee and H. J. Byrne, Toxicology in Vitro, 2014, 28, $1449-1460$.

25. OECD, Env/Jm/Mono, 46, 2010.

26. Dendritech, http://www.dendritech.com/pamam.html (accessed 01/06/2017).

27. M. Miljkovic, T. Chernenko, M. J. Romeo, B. Bird, C. Matthaus and M. Diem, Analyst, 2010, 135, 2002-2013.

28. J. C. Roberts, M. K. Bhalgat and R. T. Zera, J Biomed Mater Res, 1996, 30, 53-65.

29. N. Malik, R. Wiwattanapatapee, R. Klopsch, K. Lorenz, H. Frey, J. W. Weener, E. W. Meijer, W. Paulus and R. Duncan, J Control Release, 2000, 65, 133-148.

30. P. Watson, A. T. Jones and D. J. Stephens, Adv Drug Deliv Rev, 2005, 57, 43-61.

31. S. P. Mukherjee, F. M. Lyng, A. Garcia, M. Davoren and H. J. Byrne, Toxicol Appl Pharmacol, 2010, 248, 259-268.

32. I. Notingher, S. Verrier, S. Haque, J. M. Polak and L. L. Hench, Biopolymers, 2003, 72, $230-240$.

33. I. Notingher and L. L. Hench, Expert Rev Med Devices, 2006, 3, 215-234.

34. Z. Movasaghi, S. Rehman and I. U. Rehman, Applied Spectroscopy Reviews, 2007, 42, 493-541.

35. P. R. Leroueil, S. Hong, A. Mecke, J. R. Baker, B. G. Orr and M. M. Banaszak Holl, Accounts of Chemical Research, 2007, 40, 335-342.

36. S. Hong, A. U. Bielinska, A. Mecke, B. Keszler, J. L. Beals, X. Shi, L. Balogh, B. G. Orr, J. R. Baker, Jr. and M. M. Banaszak Holl, Bioconjug Chem, 2004, 15, 774-782. 
37. R. Zhang, K. A. Kang, M. J. Piao, Y. H. Maeng, K. H. Lee, W. Y. Chang, H. J. You, J. S. Kim, S. S. Kang and J. W. Hyun, Chem Biol Interact, 2009, 177, 21-27.

38. F. Henkler, J. Brinkmann and A. Luch, Cancers, 2010, 2, 376-396.

39. S. Brunner, T. Sauer, S. Carotta, M. Cotten, M. Saltik and E. Wagner, Gene Ther, 2000, 7, 401-407.

40. B. Nandy, M. Santosh and P. K. Maiti, J Biosci, 2012, 37, 457-474.

41. G. M. Pavan, P. Posocco, A. Tagliabue, M. Maly, A. Malek, A. Danani, E. Ragg, C. V. Catapano and S. Pricl, Chemistry - A European Journal, 2010, 16, 7781-7795.

42. M. I. Sierra, A. Valdés, A. F. Fernández, R. Torrecillas and M. F. Fraga, International Journal of Nanomedicine, 2016, 11, 6297-6306.

43. C. Gong, G. Tao, L. Yang, J. Liu, Q. Liu and Z. Zhuang, Biochem Biophys Res Commun, 2010, 397, 397-400.

44. S. V. Pirela, I. R. Miousse, X. Lu, V. Castranova, T. Thomas, Y. Qian, D. Bello, L. Kobzik, I. Koturbash and P. Demokritou, Environ Health Perspect, 2016, 124, 210 219. 


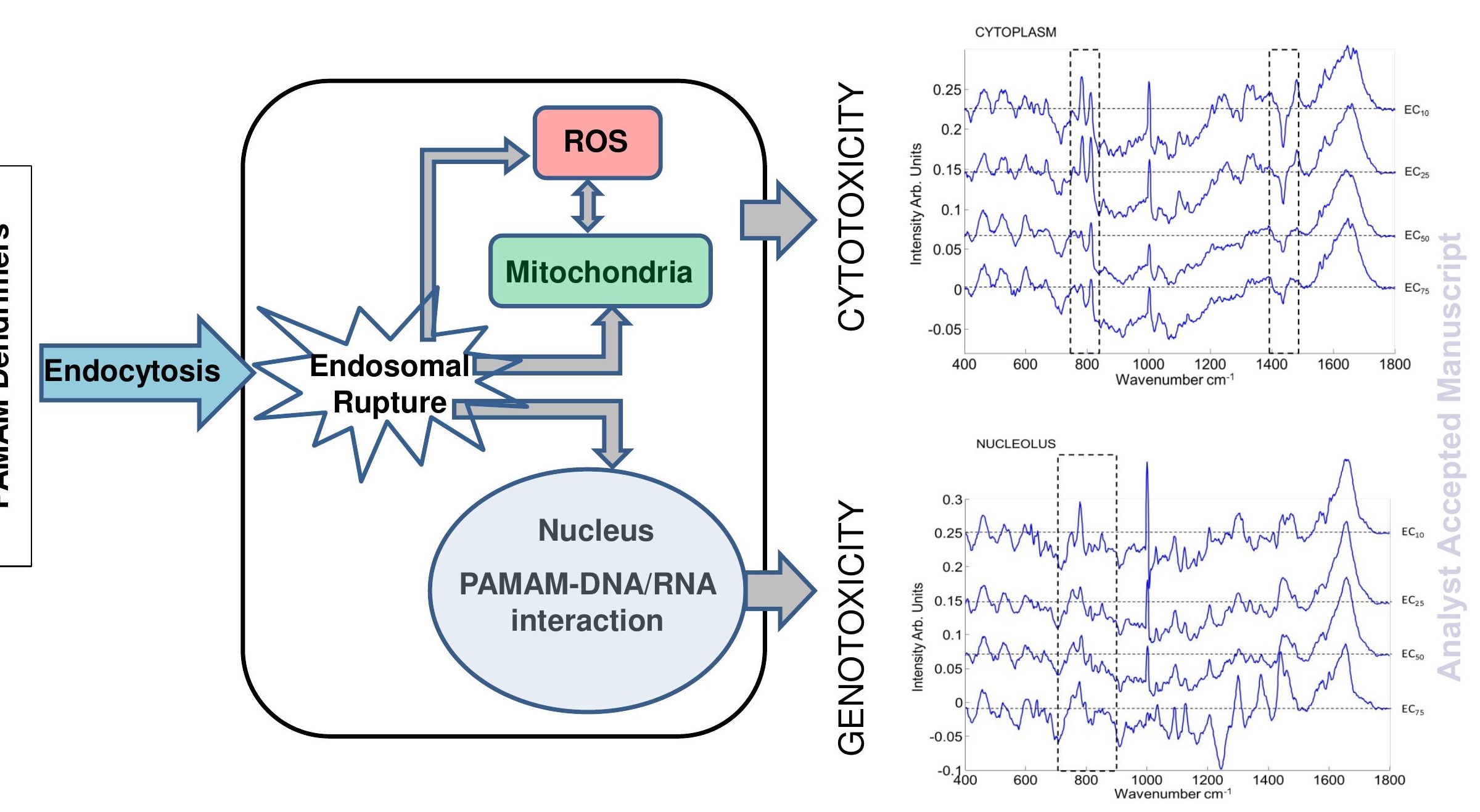

Determination of Spectral Markers of Cytotoxicity and Genotoxicity using in vitro Raman Microspectroscopy: Cellular Responses to Polyamidoamine Dendrimer Exposure 